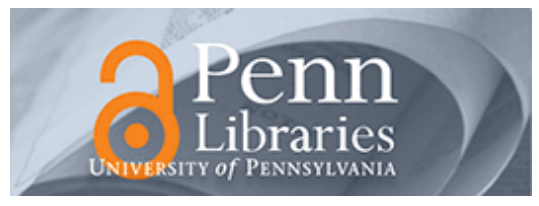

University of Pennsylvania ScholarlyCommons

\title{
When Online Reviews Meet Hyperdifferentiation: A Study of the Craft Beer Industry
}

\author{
Eric K. Clemons \\ University of Pennsylvania \\ Guodong G. Gao \\ Lorin M. Hitt \\ University of Pennsylvania
}

Follow this and additional works at: https://repository.upenn.edu/oid_papers

Part of the Marketing Commons, Operations and Supply Chain Management Commons, and the Other Education Commons

\section{Recommended Citation}

Clemons, E. K., Gao, G. G., \& Hitt, L. M. (2006). When Online Reviews Meet Hyperdifferentiation: A Study of the Craft Beer Industry. Journal of Management Information Systems, 23 (2), 149-171. http://dx.doi.org/ 10.2753/MIS0742-1222230207

This paper is posted at ScholarlyCommons. https://repository.upenn.edu/oid_papers/67

For more information, please contact repository@pobox.upenn.edu. 


\title{
When Online Reviews Meet Hyperdifferentiation: A Study of the Craft Beer Industry
}

\author{
Abstract \\ We analyze how online reviews are used to evaluate the effectiveness of product differentiation strategies \\ based on the theories of hyperdifferentiation and resonance marketing. Hyperdifferentiation says that \\ firms can now produce almost anything that appeals to consumers and they can manage the complexity \\ of the increasingly diverse product portfolios that result. Resonance marketing says that informed \\ consumers will purchase products that they actually truly want. When consumers become more informed, \\ firms that provide highly differentiated products should experience higher growth rates than firms with \\ less differentiated offerings. We construct measures of product positioning based on online ratings and \\ find supportive evidence using sales data from the craft beer industry. In particular, we find that the \\ variance of ratings and the strength of the most positive quartile of reviews play a significant role in \\ determining which new products grow fastest in the market-place. This supports our expectations for \\ resonance marketing.

\section{Keywords} \\ differentiation, online reviews, product positioning, product variety, resonance marketing, word of mouth \\ Disciplines \\ Marketing | Operations and Supply Chain Management | Other Education
}




\title{
When online reviews meet hyperdifferentiation: A study of craft beer industry
}

\author{
Eric K. Clemons • Guodong (Gordon) Gao • Lorin M. Hitt \\ clemons@wharton.upenn.edu • gaog@wharton.upenn.edu • $\underline{\text { lhitt@wharton.upenn.edu }}$ \\ The Wharton School, University of Pennsylvania
}

Extended Abstract for WISE 2004

\section{Introduction}

It has long been recognized that word of mouth can have a significant impact on sales. In the past, the effect of word of mouth has always been limited to friends and relatives. However, the advent of the Internet enabled online forums has dramatically changed the situation. Now the opinion of one customer can be read by thousands of potential buyers. Indeed, online reviews have become an important channel of product information.

In this study, we examine the impacts of online reviews on the sales of craft beers and on the growth of microbreweries. The demand for craft beer has been steadily increasing in recent years, reversing decades of consolidation of the industry in the hands of giant producers of insipid beers like Budweiser and Miller. Many factors contribute to the trend, like the increase in disposable income, an increasing interest in self-indulgent consumption and cheap luxuries, and "trading up", all of which boost demand for better craft beers. However, one important driving force is the availability of beer information online. Major brewers like Anheuser Busch spend as much as \$500 million annually on promotion, and advertising is the largest single cost of beer for these majors. Without online forums, craft beers have very few information channels to forward their product information to potential consumers and no means of responding to the media blitz of their larger competitors. The lack of product information adversely influences sales of a product, as we showed in our previous research (that is, customers are more willing to buy craft beer when they what they are getting). Thus online forums, which eliminate the "information barrier", should have significant influence on the sales of craft beers. This in turn will change the dynamics of the industrial organization. For example, by 
facilitating small firms to promote their products, online forums may foster new entries and intensify competition.

The relationship between online reviews and sales is beginning to gain attention from academic researchers. Dellarocas, Awad and Zhang (2004 working paper) find that online reviews of movies can be a good proxy for word of mouth and useful in revenue forecast. Chevalier and Mayzlin (2003 working paper) find that improvement in a book's reviews leads to increase in relative sales at that site. Existing researchers have been using measures like count of reviews, mean of ratings, and the spread of reviews across different discussion groups.

However there has been little guidance on what measures of online reviews are best correlated with growth in sales. For example, the mean of reviews may be a good predictor of quality and of sales for a vertically differentiated product, but may provide less predictive power for a horizontally differentiated product ${ }^{1}$. Another example, most current researches treat each review equally; however each individual review's influence on sales may be quite different. Lacking guidance in review measurement may confine researchers to common simple measures and limit the construction of novel measures from online reviews.

\section{Our first contribution in this research is to provide a framework to construct online}

review measures based on the following two factors: (1) a better understanding of the nature of the product; and (2) a better understanding of the behavior of reviewers. We apply this framework to the craft beer industry and construct review measures that are specific to hyperdifferentiated products. Our current preliminary results suggest that

\footnotetext{
1 The reasoning behind this may initially appear subtle, even counter-intuitive. We can generally agree product that on average gets a 4 out of 5 is probably better than one that gets a 2.5 out of 5 and we can safely assume that they are engaging in vertical competition. Two products that are engaged in horizontal competition must be viewed differently. One that gets a 3.5 with a high standard deviation may "outcompete one that gets a 4 with a very low standard deviation. That is, the one with a slightly lower mean and high standard deviation obviously has gotten very high marks from some customers and is their first choice. The beer with lower standard deviation may, likewise, be out-competed by other beers with different sets of attributes. The beer with the higher mean may be every customer's "second favorite" but have very low sales.
} 
hyperdifferentiated products are quite different from goods that employ more traditional competitive strategies.

Even after a strong correlation between measures of reviews and sales are established, we should be very cautious about any inference of causality. This is because the causality can go in several ways: (1) sales induce reviews, (2) reviews induce sales; or (3) other factors like quality drives both sales and reviews. Our second contribution is to apply several ways to examine the causality between online reviews and sales. First we use lag value to infer Granger causality; we then explore historical trend of the craft beer industry (a before-after comparison); at last we use local internet penetration as an instrument for online reviews. Since it is unlikely that Internet penetration is driven by the beer consumption behavior, and high Internet penetration facilitates review behavior, variation in the level of Internet penetration provides us with an instrument that can be used to infer causality between online reviews and sales. To employ the last approach, we first need to establish the correlation between Internet penetration and online reviews. We also need to control for other confounding factors that influence both sales and internet penetration. We address this issue by including a bunch of demographic variables from Census 2000.

\section{Our third contribution will be to examine online forums' impact on the industry}

structure. As we agued before, online forums have the potential to facilitate small firms to enter the industry by eliminating information barrier between firm and potential customers and thus facilitating competition. However, online forums can also deter entry because now consumers can more easily locate the best product in a niche, and new firms may be more reluctant to enter unless their product is demonstrably superior in some way. The implication of online forums should be different for low quality firms and high quality firms. We would also like to examine whether firms in high Internet-penetration area enjoy more competitive advantage because they have more local reviewers who are able to obtain the beer and post a review.

In summary, in a detailed study of craft beer industry, we will address the following three questions that are related to online reviews: 
(1) What measures of online reviews should be applied to predict sales?

(2) Are there causality relationships between online reviews and sales?

(3) Overall, how have online forums (and more broadly, the Internet) changed the dynamics of industrial organization of the craft beer industry?

\section{Data}

We are fortunate to have been able to obtain rich data of the craft beer industry, which allows us to pursue our goals set up in part 1. Our data come from three parts:

(1) Our online review data come from ratebeer.com. We obtained all the 108,644 ratings for 1159 US craft brewers and self-reported distribution data (5551 different zip codes). Each review contains detailed reviewer information.

(2) Sales data are provided by Association of Breweries from year 1995-2003. For each year around 300 major craft brewers' sales data are available, although it is not a complete panel.

(3) Internet penetration data are from Current Population Survey (CPS) 1995-2001. Other demographic control variables are obtained from Census 2000.

\section{Preliminary results}

(1) Although the count of reviews posted for a single beer is a good predictor for sales, the average of ratings is not correlated with sales in a statistically significant way. That is, beers that are more widely sold are more frequently rated (no surprise), but the average rating is not correlated with higher sales. This second result is contrary to conventional wisdom, but quite consistent with our projection based on hyperdifferentiation theory.

(2) Interestingly, we find that average and the standard deviation of ratings are significantly correlated with sales growth rate $(p<.05$ even in a relatively small sample with 134 observations). This shows that for a category of differentiated products engaged 
in horizontal competition, it is more important to be the first choice of a significant segment than to be an acceptable substitute product for a large number of customers.

(3) Newly entered firms gain their first 10 reviews mostly from local consumers. Entrants in year 2003 obtain faster reviews (the time for a new firm to get the first 20 reviews) than in year 2000. This helps us understand how online forums help establish the entrant's reputation.

(4) Internet penetration is significantly correlated with the number of reviews in an area, even after controlling for other demographic variables like and population, income;

(5) Firms that locate in high Internet penetration areas tend to distribute their products more widely. Combined with (3), (4) and the observation that Internet penetration of a certain area is correlated with number of reviewers from that area, these results suggest that online forums may play an important role in fostering newly entered high quality firms to grow faster. We are least confident of this result, however; alternative explanations are simply that high internet penetration regions are, of course, more urban on average and more wealthy on average. More urban means that there will be more potential local customers, which we have seen is correlated with early reviews, which is correlated with more rapid sales. Likewise, consumers in more affluent regions are more likely to try luxury products, leading to more reviews.

\section{Future plan}

In the months preceding the conference we intend to

(1) further refine our dataset;

(2) complete the framework of measurement selection for online reviews;

(3) construct better measures from online reviews based on our framework;

(4) implement other empirical models outlined in part 1. 